\title{
SELECTION AND ASSESSMENT OF THE RELEVANT DATA FOR REDUCING THE NUMBER OF RED-LIGHT RUNNING
}

\author{
Milan Vujanić, Dalibor Pešić, Boris Antić, Nenad Marković \\ Faculty of Transport and Traffic Engineering, University of Belgrade, Serbia \\ Submitted 21 March 2015; resubmitted 13 May 2015; accepted 17 May 2015; \\ published online 11 April 2016
}

\begin{abstract}
Although traffic light controlled intersections separate, the traffic flows by time and space, road traffic accidents still occur, usually due to Red-Light Running (RLR). In order to define countermeasures to solve this problem, it is necessary to collect and analyze certain data that will indicate type of measures, which should be applied. In this paper, it was done on the example of one 3-leg and one 4-leg intersection where citizens provided information about frequent RLR to the City Administration of Belgrade (Serbia). The statistical significance of differences between the collected data was tested by ANOVA analysis and by PostHoc Tukey test, which showed that forecasting of second of RLR after red-light onset could effectively be conducted by Cubic distribution. In order to define the so-called RLR risk indicator for the intersection, the use of the Danger Degree (DD) indicator, that presents the rate between the number of dangerous situations caused by RLR and the total number of RLR, was proposed.
\end{abstract}

Keywords: signal controlled intersections; red-light running (RLR); second after red-light onset; traffic accidents; danger degree; countermeasures.

\section{Introduction}

The basic idea of introducing traffic signals at intersections is to separate space and time of opposite traffic flows and to give priority to one direction over the other. In theory, an accident could not happen at signalized intersection because direction flows are separated, but accidents still do occur. Abdel-Aty et al. (2005) found that an average of 9.6 crashes occur at signalized intersections per year, compared to two crashes per year where traffic control is obtained by the stop or yield signs. The accidents that happen at signalized intersections as a result of vehicle stopping at the Red-Light (RL) are rear-end collisions. Side impact accidents usually occur due to Red-Light Running (RLR). The consequences of those side impact accidents are more severe due to lack or lower side protection for the passengers.

RLR is one of the main problems in traffic safety. Therefore, the Commission of the European Communities labeled RLR along with speeding problems, drunk-driving and not using a seatbelt as particularly significant problems in road safety through the Proposal for a Directive COM(2008) 151 final (EC 2008). Çelik and Senger (2014) showed influence of factors on the occurrence of traffic accidents, as well as the fatal or non-fatal accidents, depending on the development of the region, but also in relation to the surrounding region, in example of Turkey. The size of the problem can be presented by reviewing data showing the number of the committed RLR as well as the consequences following such offenses. According to Retting et al. (2002) it is estimated that around 260,000 road accidents happen each year as a result of RLR, of which 750 are fatal accidents. Smith et al. (2000) found that in 1997 in three American cities, there were over 789000 crashes at signalized intersections, of which 97000 were attributed to RLR, and 961 fatalities were attributed to RLR. In Serbia, without Red-Light Cameras (RLC), for five-year period (2003-2007), 89007 RLR violations were registered, that means about $3 \%$ of all violations (Pesic et al. 2011). Porter and England (2000) observed more than 5,000 drivers who passed through six traffic controlled intersection in three Southeast Virginia cities and found that 35.2\% of observed light cycles had at least one RLR. Retting et al. (1998) concluded that on a busy intersection in Arlington (Virginia) there was one RLR every $12 \mathrm{~min}$ during normal hours and one RLR every 5 min during morning hours.

On the other hand, a lower volume intersection had 1.3 violation per hour and 3.4 in the evening peak hour (Retting et al. 1998). In his work Awadallah (2013) ana- 
lyzed the possibility of reducing time losses and improving safety level at signalized intersections, depending on the length of all the red and yellow period in the cycle of the traffic lights signal plan. He showed that by using active monitoring of the speed on the approaches, but also of the density is possible to optimize the length of period of the cycle. In addition, Awadallah (2013) showed how to enhance improve safety at an intersection and reduce time losses.

Several studies researched effects of the implemented measures for RLR reduction. Therefore, Palat and Delhomme (2012) have cited that in France in 2007 RLC recognized 223612 red- and yellow-light violations. Studies conducted in the US by Retting et al. (1999a, $1999 b$ ) were trying to establish the effect of RLC on the occurrence of traffic accidents due to RLR and shown that the introduction of RLC affects the reduction of accidents caused by RLR by $44 \%$ or $22 \%$ respectively. Also, Smith et al. (2000) and Fitzsimmons et al. (2009) examined effects of automated enforcement and found significantly reducing in RLR, i.e. Smith et al. (2000) found reducing in $20 \%$ of RLR, and Fitzsimmons et al. (2009) found almost 25 times higher RLR violations at location without RLC than at locations with RLC, respectively.

Some of research such as Fitzsimmons et al. (2007) summarized magnitude of RLR problem through number of RLR accidents and consequences of those accidents, and effects of RLR camera enforcement programs through evaluation of reduction in crashes before and after implementation of the RLC. Because of lack of accident, data evaluation was done by comparing RLR violation at camera-instrumented intersection to a group of control intersection. For this purpose, a generalized linear model was used to determine statistical significance of the differences between violations among the study locations with RLC and the control intersection. It was shown, that approaches with RLC had a statistically significant lower number of RLR violation and RLR crashes than approaches without RLC. In addition, conclusion of the report was that reduction depends on volume and movement. For example, with a volume of 200 vehicles per hour, right movement without camera has 9.3 violations per hour and with camera, this number was 0.4 violations per hour. Similar reports, such as Hallmark et al. $(2011,2012)$, highlighted RLR problem and some countermeasures for RLR reducing, i.e. signal operating, motorist information, physical improvement and enforcement are proposed.

Other report (Adams, VanDrasek 2009) highlighted that first of all in solving RLR problem is to find if there is RLR problem on specified intersection in particular or in general. After that, it is important to find appropriate data of RLR problem such as right-angle crashes etc, and if there is lack of those data, data about violations could be helpful for determining magnitude of problem and for proposing adequate measures.

Other research (Yan et al. 2009) study if there is any impact of pavement marking ('signal ahead') on drivers' behavior at signalized intersections, especially impact on RLR, and it was found that the marking can contribute to a lower RLR rate. Similar as Yan et al. (2009), Awadallah (2009) suggested pavement marking with delineation of a yellow transverse line at the calculated decision line, where drivers should decide to stop or to move through the intersection.

Limanond et al. (2010) have researched impacts of countdown timers on traffic operations, but also driver behavior at a signalized intersection and found that timers decrease number of violation for $50 \%$ (mean time of RLR was decreased or about $25 \%$, from 4.13 to 3.08 s) after the onset of the red phase. Ma et al. (2010) have also examined effects of countdown devices on RLR and found significantly reducing in RLR. On the contrary, Long et al. (2011) have found that countdown timers increase the number of red-light violations.

Other authors have studied other measures' effects, as research conducted by Schultz et al. (2007) that have showed that overhead dynamic advance warning signal change number of RLR violation statistically significant. Furthermore, Wu et al. (2012) have examined RLR done by electric bike riders and cyclists at urban intersection in China and have researched if there was any impact of cyclist's characteristics (age, gender, group size, etc.) on RLR. In addition, Wu et al. (2012) have found that cyclists often made RLR at the beginning and at the end of red phase.

Yan et al. (2005) highlighted that there are correlation between accidents happened on traffic light intersection and data such as: drivers age (the youngest drivers have the highest red-light violations rate), drivers type (truck drivers have high red-light violation rate), intersection type (Y-shaped intersections have a higher percentage of violations), etc. Besides, average traffic flow speeds, traffic volume rate, the green split, the number of through and crossing lanes, signal coordination, vehicle's approaching speed, driver's age and gender, etc, are also contributing factors that have important influence on driver's decision at intersections (Liu et al. 2012). Similarly, Huang and Chin (2009) identified a number of significant factors contributing to RLR crash propensity for different driver age, gender groups and vehicle types.

After implementation of measures for decreasing number of RLR Smith et al. (2000) suggest that several measures of effectiveness have to be used to evaluate the system's efficacy: red-light violations frequency, cost savings over manual enforcement, public acceptance, institutional barriers and maintenance and operational costs.

Research about RLR were often conducted on the field (field data collection) - video recording, photo shooting (RLC), observation, etc. (Elmitiny et al. 2010; Wu et al. 2012, Saunier, Sayed 2007, Ismail et al. 2009, Limanond et al. 2010). Tiwari et al. (2007) also used a video camera but to examine pedestrian behaviour at signalized intersections. Furthermore, Johnson et al. (2011) and Phillips et al. (2011) used video recording to analyze cyclists' behavior at signalized intersections.

In recent research by De Luca et al. (2011) and De Luca (2015) advanced statistical techniques such as cluster algorithms and artificial neural network was used 
to determine danger level of hazard zone and danger black spots.

Having in mind previously overviewed papers and reports about RLR we have focused on two issues in this paper. First, what kind of data has to be collected about RLR to indicate countermeasures' proposal and the second one is to find appropriate indicator to measure danger or risk happened if RLR occurred.

In accordance with the previously mentioned, the necessary number and types of data that have to be collected from the field of RLR violation was proposed, as a basis for defining measures. For example, RLR frequency, in particular second after the red-light onset, may indicate that extending of the duration of the protective time and yellow-light would reduce number of RLR. By implementing the counters that would show to drivers the time left to red-light onset, drivers could be in a position to predict the occurrence of red-light and to adjust their speed in time to stop. RLC, as an enforcement measure, could more effectively solve the problem of RLR if the number of RLR per second is evenly dispersed during the red phase, etc.

For defining priorities in the implementation of RLR countermeasures, it is important to know the risk of accidents due to RLR, which could be defined using the rate of conflicts caused by RLR and the total number of RLR. Because of that an indicator that could evaluate the risk of an accident caused by RLR in an efficient manner, has to be proposed.

\section{Methods and Materials}

For defining RLR problem and proposing adequate countermeasures, collectioning data from the field was conducted by recording movement through the intersection using digital cameras. For this research, only video recording was used, and crash data analysis was not used because of the fact that the proposed method has to be proactive, what could determine RLR problem without waiting for the accidents to happen. In future, the results of the proposed method could be compared to the crash data if those data existed. In Fig. 1 it was given algorithm of applied research methodology.

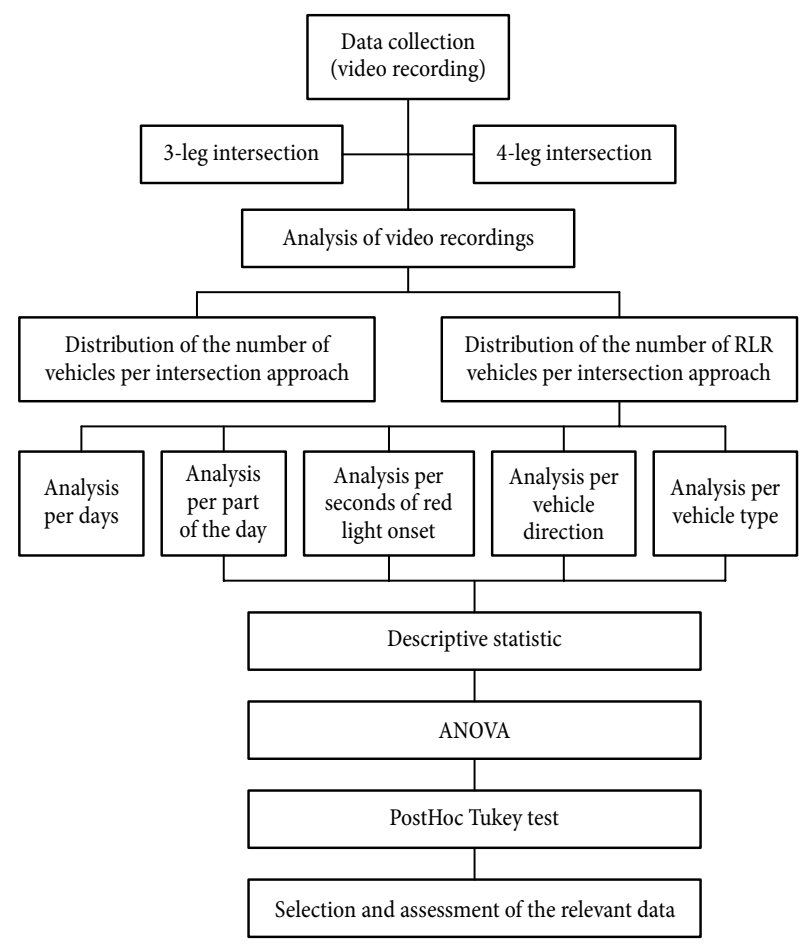

Fig. 1. Algorithm of researched method

In order to allocate the important elements for RLR countermeasures, a survey was conducted at the selected locations, for which the City Administration of Belgrade (Capital city of Serbia with a population of 1.5 million from 2010 census) received information by its citizens of frequent RLR. First location is 3-leg intersection (Vojvode Stepe street and Ljuba Vučkovića street - Fig. 2a), and the second one is 4-leg intersection (Vojvode Stepe street, Save Maškovića street and Kružni Put street Fig. 2b).

On the 3-leg intersection, all approaches to intersection are two-way streets with one lane per direction. Every approach has a pedestrian crossing and a stop line. On the 4-leg intersection, all approaches to the intersection are two-way streets, three of them are with one lane per direction, and one is with three lanes per
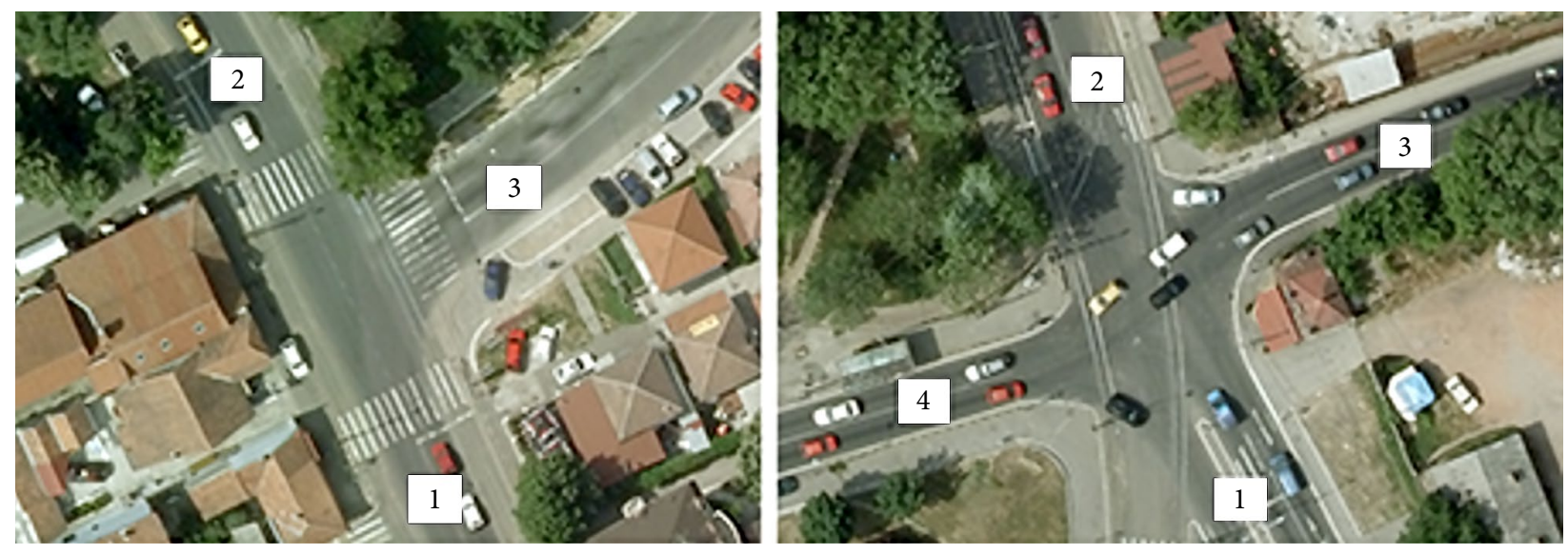

Fig. 2. Researched locations: a - 3-leg intersection; b - 4-leg intersection 
direction (one lane for left turn). The posted speed limit is $40 \mathrm{~km}$ per hour, and RLR enforcement at researched intersection is conducted very rarely by 'live force', which means that traffic police officers controlled and punished RLR very rarely. In order not to affect the drivers' behaviour, recordings were done by using hidden cameras (in parked vehicles), with one digital camera per one approach. After recording, video files from the cameras were transferred into PC files. This way of analyzing data makes the opportunity to make afterwards researching, but also to have possibility of slow-motion of vehicle movement through the intersection. This is especially important if some RLR situation is not clear. Researchers examined video files on PC and registered all necessary data about every vehicle that moved through the intersection in a way to determine where and when vehicle cross the traffic light pole. If after entering the intersection, a dangerous situation happened, those data were also registered. A vehicle that crossed the traffic light pole, when it was red-light onset, was registered as RLR violator. Data about time (second after red-light onset) when driver of particular vehicle made RLR, vehicle category, direction of movement through intersection and potentially dangerous situation were also registered.

Data of RLR, for each intersection were collected over four weeks period, from 09/12/2011 to 10/09/2011 for 3-leg intersection and from 08/27/2012 to 09/23/2012 for 4-leg intersection, considering each approach in four different periods of the day: morning from 7:00 to 9:00, noon from 11:00 to 13:00, afternoon from 15:00 to 17:00 and evening from 24:00 to 02:00. Morning period from 7:00 to 9:00 was selected because in that time people go to work, and then is highest frequency on intersections. Noon period from 11:00 to 13:00, was selected because that is period with average frequence. Afternoon period from 15:00 to 17:00, was selected because in that time people go from work to other destinations (home, entertainment, relaxation, etc), and then is highest frequency on intersections. Late evening period, from 24:00 to 02:00 was selected, because traffic volume and police enforcement are very low in that period, which leads to higher number of RLR violation at night. Late evening period, from 24:00 to 02:00 was selected, because traffic volume and police enforcement are very low in that period, which leads to higher number of RLR violation at night. Because of data collection at night, it is important to have good night visibility and on the researched intersection, there is a good visibility due the existing light poles. During the research period, on 3-leg intersection over 90486 vehicles moved through the intersection, of which 43419 vehicles passed in direction 1 , 40595 passed in direction 2 and 6472 vehicles passed in direction 3. On the 4-leg intersection, during the reasearch period over 178089 vehicles moved through the intersection, of which 47362 vehicles passed in direction 1, 54653 vehicles passed in direction 2,39826 vehicles passed in direction 3 and 36248 vehicles passed in direction 4. Signal timing plans at both intersections do not change during the day, and the duration of the cycle is 90 seconds for both intersections (signal timing plan - Fig. 3). According to Serbian standard for traffic light project procedures, yellow time-period lasts for 3 seconds and red-yellow light period lasts for 2 seconds. Signal timing plan for the 3-leg intersection have all-red clearance interval from 36th to 38th second of cycle, and 4-leg intersection have all-red clearance interval from 44th to 46th second of cycle.

The collected data were analyzed by descriptive statistics and ANOVA test was conducted to find whether there were statistically significant differences in approaches considering RLR. Analysis was done only for vehicles that passed through the red-light because the Traffic Safety Law in Serbia does not prohibit yellowlight runing.

Dangerous situations is considered as every event where there is a potential conflict between traffic partici-

a)

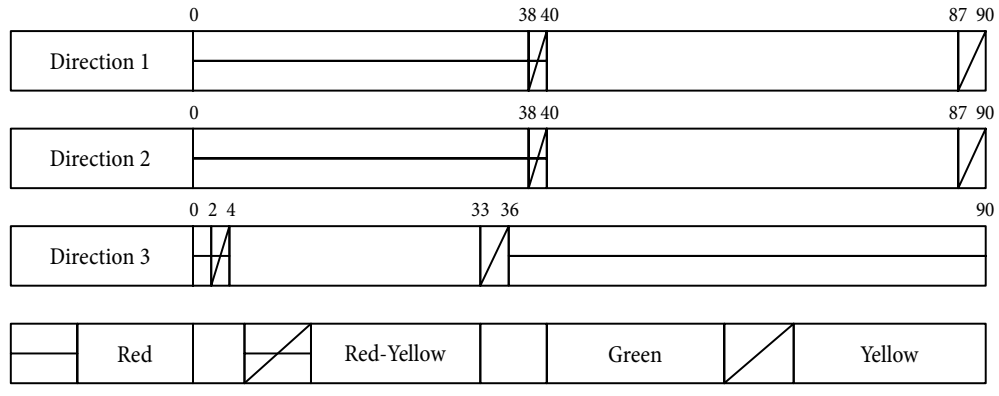

b)

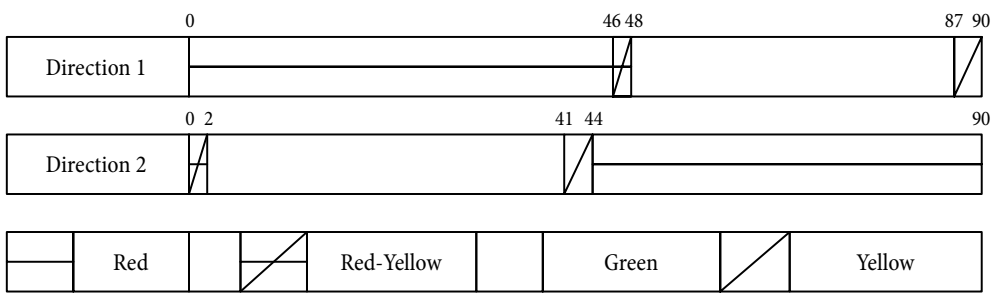

Fig. 3. Signal timing plan: a - 3-leg intersection; b - 4-leg intersection 
pants (intensive braking, sudden stop, sudden acceleration, etc), on the same approach to intersection or from the different approaches to intersection. For purposes of comparability between intersections, the factor Danger Degree (DD) is defined. DD indicates the risk of turning RLR into an accident, and presents the rate between the number of dangerous situations caused by RLR and total number of RLR.

\section{Results}

At the 3-leg intersection on green-light 87702 vehicles (96.9\%) moved through, 2231 vehicles $(2.5 \%)$ moved through yellow-light and 553 vehicles $(0.6 \%)$ made RLR. On 3-leg intersection at the approach 143419 vehicles moved through the intersection, of which 261 were RLR, at the approach 2, there were 40595 vehicles that moved through the intersection of which 264 were RLR, and at the approach 3, 6472 vehicles moved through the intersection, of which 28 were RLR. At the 4-leg intersection on green-light 168170 vehicles (94.4\%) moved through, 8657 vehicles $(4.9 \%)$ moved through yellow-light and 1262 vehicles $(0.7 \%)$ made RLR. At the approach 1 , 47362 vehicles moved through the intersection, of which 363 were RLR. At the approach 2, there were 54653 vehicles that moved through the intersection of which 388 were RLR. At the approach 3, 39826 vehicles moved through the intersection of which 236 were RLR At the approach 4, 36248 vehicles moved through the intersection of which 275 were RLR. In further analysis, we used absolute numbers of RLR because in our opinion, RLR analysis in absolute number is more important, compared to RLR rates analysis (relative numbers). For example, it is better to save 10 lives at the intersection with $100 \mathrm{RLR}$, than 5 lives at the intersection with 10 RLR, although rates could tell a different story.

The summary of the collected data about RLR is shown in Table 1. In particular, the data were collected and analyzed per days, per part of the day, per seconds of RLR after red-light onset, per vehicle type and per direction of vehicle movement through the intersection. Considering the observed differences between approaches it is necessary to determine if there are any statistical significances of the collected RLR data. Also considering features of the investigated intersections, where there is one, so-called main direction (1-2), and a secondary approach (3-4), it is necessary to notice whether there are significant differences between approaches which was done by ANOVA analysis using SPSS software package. For defining and predicting the second of RLR after the red-light onset, a matching test with statistical distributions was carried-out.

All recorded RLR at the 3-leg intersection were distributed as follows, $47.2 \%$ at the approach 1, 47.7\% at the approach 2 and $5.1 \%$ at the approach 3, and at the 4-leg intersection were distributed as follows, $28.8 \%$ at the approach 1, 30.5\% at the approach 2 and $18.7 \%$ at the approach 3 and $21.8 \%$ at the approach 4 . Descriptive statistics (Table 2) have showed that there is a difference in the number of RLR observed by the approaches, for both intersections. To verify the results, an additional ANOVA analysis was conducted (Table 3) according to which $F(2,18)=29.857$ ( $p<0.01)$ (for 3-leg intersection) and $F(3,24)=7.161(p<0.01)$ (for 4-leg intersection). PostHoc Tukey test (Table 4) confirmed the difference for 3-leg intersection, between approaches 1 and 3 and approaches 2 and 3 on the level of significance $p=0.05$, while between approaches 1 and 2 there is no significant difference. For 4-leg intersection PostHoc Tukey test (Table 4) confirmed the difference between approaches 1 and 3, approaches 2 and 3, and approaches 2 and 4 on the level of significance $p=0.05$, while between approaches 1 and 2, approaches 1 and 4 and approaches 3 and 4 there is no significant difference.

ANOVA analyses were also applied on the following data: RLR frequencies per days, per part of the day, per seconds of RLR after RL onset and per vehicle category. Vehicle movement through the intersection was observed using RLR frequency of different movement through the intersection.

ANOVA analyses for 3-leg intersection showed that there was no statistical significiance between days of the week $(F(6,14)=0.876(p=0.536))$, or the period of the day $(F(3,8)=2.47(p=0.139))$, but it still shows that there is some dependence (Tables 5 and 6 ). In $46.4 \%$ of RLR per days of the week there is statistical significance, and looking at the descriptive statistics (and frequencies) it could be concluded that on Sundays (7.6\%) almost half of the RLR occurred, compared to the other days of the week (from $11.6 \%$ to $17.9 \%$ ). Although ANOVA analysis does not show statistical dependence of the number of RLR per the part of the day at least at the 0.05 level, $86.1 \%$ RLR have statistical significance. Looking at the frequencies, less RLR occurs at night (11.9\%) and more in the afternoon (35.4\%). However, statistically significant differences arise when considering a second of RLR after red-light onset $(F(7,16)=85.741$ $(p<0.01)$ ) (Table 7) and when considering categories of vehicles (Table 8) that did $\operatorname{RLR}(F(4,10)=215.736(p<$ $0.01)$ ). According to the vehicle movement through the intersection $72.7 \%$ of all RLR went straight, $11 \%$ were turning left and $16.3 \%$ were turning right.

For 4-leg intersection, ANOVA showed that there were statistical differences between days of the week $(F(6,21)=4.266(p=0.006))$, or the period of the day $(F(3,12)=11.665(p=0.001))$. ANOVA analysis also shows statistical dependence (Table 5) of the number of RLR per the part of the day (Table 6). Looking at the frequencies, less RLR occurs at night (17.8\%) and more in the afternoon (35.7\%).

However, there are statistically significant differences when considering a second of RLR after redlight onset $(F(7,24)=51.068(p<0.001))$ (Table 7) and when considering categories of vehicles that did RLR $(F(4,15)=220.701(p<0.001))$ (Table 8$)$. Analysis of vehicle movement through the 4-leg intersection shows that $72.7 \%$ of all RLR went straight, $11 \%$ were turning left and $16.3 \%$ were turning right. 


\begin{tabular}{|c|c|c|c|c|c|c|c|c|c|c|c|c|c|c|c|c|c|c|c|c|c|}
\hline \multirow{8}{*}{ 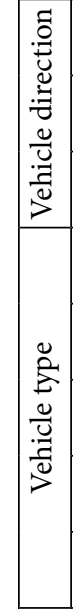 } & ไบชి!! & & 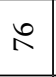 & $\overrightarrow{\text { ते }}$ & 0 & $\because$ & $\Xi$ & 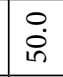 & \& & $\stackrel{n}{0}$ & & \multirow{2}{*}{\multicolumn{2}{|c|}{ 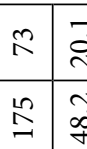 }} & \multirow{2}{*}{$\begin{array}{l}\stackrel{0}{=} \\
\widetilde{\sigma}\end{array}$} & \multirow{2}{*}{\begin{tabular}{|l|}
$\grave{\partial}$ \\
$\dot{\lambda}$ \\
$\dot{0}$ \\
$\dot{0}$
\end{tabular}} & \multicolumn{2}{|c|}{\begin{tabular}{c|c}
$c$ & $\overrightarrow{0}$ \\
& $\stackrel{n}{\circ}$ \\
+ & $a$
\end{tabular}} & \multirow{2}{*}{$\begin{array}{l}\vec{\infty} \\
\vec{m}\end{array}$} & \multirow{2}{*}{$\begin{array}{l}\stackrel{2}{2} \\
\text { กे } \\
\stackrel{m}{=}\end{array}$} & \multirow{2}{*}{ 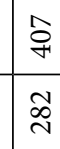 } & \multirow{2}{*}{ 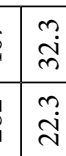 } \\
\hline & भગ & & 0 & $\because$ & Fे & $\stackrel{\infty}{\stackrel{\infty}{\perp}}$ & $\Xi$ & 官 & 6 & $\stackrel{\circ}{\exists}$ & & & & & & & 官 & & & & \\
\hline & 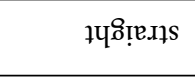 & & $\stackrel{\infty}{\infty}$ & 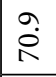 & $\vec{\sim}$ & 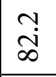 & 0 & $\because$ & శ̊ & $\hat{i}$ & & $\stackrel{2}{=}$ & 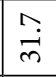 & 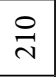 & $\vec{H}$ & 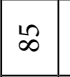 & $\begin{array}{l}0 \\
\dot{0} \\
\tilde{n}\end{array}$ & $\tilde{b}$ & ๓̊̀ & in & $\begin{array}{l}\ddot{H} \\
\text { f }\end{array}$ \\
\hline & snq & & 6 & $\stackrel{m}{i}$ & in & $\stackrel{9}{-1}$ & $\neg$ & $\stackrel{\bullet}{i}$ & $\simeq$ & $\tilde{i}$ & & 눙 & $\stackrel{+}{+}$ & $\simeq$ & $\vec{m}$ & $\stackrel{\sim}{\sim}$ & $\stackrel{2}{\varrho}$ & $\stackrel{\infty}{=}$ & $\ddot{6}$ & R & in \\
\hline & әрКј.оџош & & n & $\exists$ & in & 9 & $m$ & $\hat{\circ}$ & $=$ & $\stackrel{\circ}{i}$ & & \& & $\stackrel{\stackrel{i}{I}}{\stackrel{H}{J}}$ & $F$ & $\stackrel{0}{0}$ & $\stackrel{\sim}{\sim}$ & $\stackrel{0}{0}$ & nิ & $\stackrel{n}{\longrightarrow}$ & $\stackrel{\infty}{\sharp}$ & $\stackrel{\beth}{=}$ \\
\hline & yวn.t] & & $\vec{\sim}$ & $\infty_{\infty}$ & $\stackrel{\infty}{m}$ & $\stackrel{+}{\underset{+}{J}}$ & $n$ & $\hat{\circ}$ & 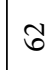 & $\stackrel{\sim}{\exists}$ & & $\Xi$ & ले & $\stackrel{\infty}{-}$ & $\stackrel{6}{\circ}$ & 2 & $\vec{\infty}$ & $\ddot{\sim}$ & $\stackrel{+}{\infty}$ & ה & மे \\
\hline & $\Lambda \cap S$ & & $\stackrel{0}{-1}$ & $\overrightarrow{6}$ & $\simeq$ & $\stackrel{n}{+}$ & $\neg$ & $\stackrel{\bullet}{r}$ & ते & in & & 6 & $\begin{array}{l}10 \\
\infty \\
\infty\end{array}$ & 8 & 㶽 & के & 点 & \& & $\underset{0}{*}$ & ટे & $\stackrel{b}{\dot{0}}$ \\
\hline & 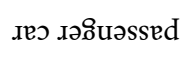 & & $\stackrel{n}{\sim}$ & $\begin{array}{l}\vec{i} \\
\underset{\infty}{ }\end{array}$ & 芩 & $\stackrel{m}{\stackrel{2}{N}}$ & ণ & $\stackrel{+}{\stackrel{n}{n}}$ & $\ddot{\vartheta}$ & নূ & & $\overrightarrow{\widetilde{N}}$ & $\hat{\tilde{\theta}}$ & $\stackrel{\hat{n}}{n}$ & సֶ. & $\vec{m}$ & \begin{tabular}{|l|}
$n$ \\
10 \\
$n n$
\end{tabular} & $\stackrel{\mathscr{I}}{\cong}$ & 艿 & $\sqrt[5]{ }$ & $\stackrel{\text { ?̊ }}{8}$ \\
\hline & $\infty$ & & $\stackrel{n}{m}$ & $\ddot{\ddot{g}}$ & $\mathscr{F}$ & $\stackrel{n}{0}$ & in & $\stackrel{9}{\Lambda}$ & $\infty$ & $\begin{array}{l}0 \\
\text { in }\end{array}$ & & $F$ & $\stackrel{n}{=}$ & กิ & $\stackrel{\oplus}{\sim}$ & in & $\begin{array}{l}n \\
\mathbb{N}\end{array}$ & $\vec{m}$ & $\stackrel{m}{=}$ & $\stackrel{\infty}{=}$ & 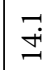 \\
\hline & $n$ & & N & $\stackrel{\infty}{0}$ & $m$ & $\exists$ & 0 & $\because$ & in & ò & & $\sim$ & $\stackrel{0}{0}$ & in & $\stackrel{m}{-}$ & 0 & $\because$ & 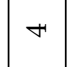 & $\stackrel{n}{-}$ & $=$ & ò \\
\hline है & 6 & & $\mathrm{~N}$ & $\stackrel{\infty}{\circ}$ & 0 & $\stackrel{m}{i}$ & 0 & $\because$ & $\infty$ & $\stackrel{\sharp}{-}$ & & N & $\ddot{0}$ & - & ? & 0 & $\because$ & $r$ & $\stackrel{n}{-2}$ & $n$ & $\stackrel{\circ}{\circ}$ \\
\hline 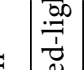 & in & & N & $\stackrel{\infty}{0}$ & $r$ & $\stackrel{4}{-1}$ & r & $\vec{\pi}$ & $\infty$ & $\stackrel{4}{-}$ & & in & $\stackrel{4}{-}$ & $n$ & $\stackrel{\infty}{0}$ & in & $\vec{i}$ & $\infty$ & $\stackrel{a}{i}$ & $\vec{\sim}$ & $\cong$ \\
\hline 莺 & H & & $a$ & $\stackrel{\sharp}{m}$ & $\stackrel{2}{-1}$ & in & $\neg$ & $\stackrel{\bullet}{r}$ & $\stackrel{2}{\sim}$ & $\stackrel{\ln }{+}$ & & $a$ & $\stackrel{n}{i}$ & $=$ & $\stackrel{\infty}{i}$ & $\Xi$ & भे & $\stackrel{\infty}{-}$ & ถุ & กิ & 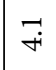 \\
\hline : & $m$ & & 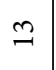 & in & $\simeq$ & $\stackrel{4}{+}$ & - & $\stackrel{\bullet}{\dot{r}}$ & $\stackrel{i}{i}$ & $\stackrel{\curvearrowright}{+}$ & & $\stackrel{2}{-1}$ & 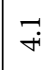 & $\Xi$ & $\stackrel{b}{\dot{m}}$ & $\stackrel{i}{i}$ & $\stackrel{\stackrel{\circ}{\rightleftarrows}}{=}$ & F & $\stackrel{m}{\stackrel{m}{2}}$ & ลे & $\curvearrowright$ \\
\hline & N & 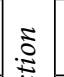 & $i n$ & $\overrightarrow{\dot{\lambda}}$ & in & $\begin{array}{l}0 \\
\dot{\sim} \\
\text { in }\end{array}$ & $m$ & $\hat{\circ}$ & $\stackrel{\Perp}{=}$ & $\begin{array}{l}\infty \\
\stackrel{\text { iे }}{ }\end{array}$ & 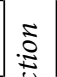 & $\stackrel{\varrho}{\varrho}$ & 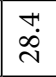 & $\stackrel{\bullet}{=}$ & ڤे & กิ & ส & $\pi$ & $\begin{array}{l}\infty \\
\dot{a} \\
\dot{i}\end{array}$ & કี & $\vec{\Delta}$ \\
\hline & - & 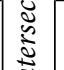 & $\stackrel{q}{\exists}$ & $\begin{array}{l}\infty \\
\dot{H} \\
\dot{1}\end{array}$ & $\underset{\Xi}{\stackrel{J}{J}}$ & $\begin{array}{l} \\
\end{array}$ & $\stackrel{0}{2}$ & त) & $\stackrel{\infty}{\sim}$ & 䚄 & 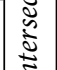 & $\begin{array}{l}\infty \\
\infty \\
\infty\end{array}$ & $\stackrel{\sim}{3}$ & $\stackrel{\infty}{\infty}$ & $\stackrel{\curvearrowright}{\stackrel{2}{f}}$ & $\infty$ & 㫄 & à & $\ddot{m}_{n}$ & 苋 & $\stackrel{\vartheta}{\dot{\gamma}}$ \\
\hline & 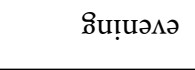 & $\overrightarrow{\frac{Q}{d}}$ & ลิ & $\exists$ & Әे & $\stackrel{\circ}{=}$ & $\infty$ & $\begin{array}{l}b \\
\infty \\
\text { id }\end{array}$ & 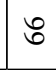 & $\stackrel{9}{=}$ & $\frac{\infty}{4}$ & $q$ & $\stackrel{\infty}{=}$ & สิ & $\stackrel{0}{\dot{\omega}}$ & ชิ & $\begin{array}{l}n \\
\stackrel{2}{0} \\
\text {. }\end{array}$ & $\stackrel{\infty}{i n}$ & $\overrightarrow{\vec{v}}$ & $\stackrel{\sim}{\sim}$ & $\stackrel{\infty}{\cong}$ \\
\hline 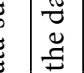 & иoouıəyе & & นn & $\begin{array}{l}\ddot{H} \\
\dot{b}\end{array}$ & 2 & $\begin{array}{l}0 \\
\dot{m} \\
m\end{array}$ & 6 & $\stackrel{+}{i}$ & 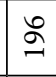 & 葱 & & ભે & $\stackrel{m}{\dot{m}}$ & $\stackrel{\simeq}{\Omega}$ & ஸุ' & $\hat{0}$ & 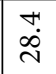 & 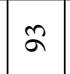 & $\underset{\infty}{\infty}$ & 孚 & 㝕 \\
\hline 嵅 & uoou & & $\stackrel{0}{1}$ & $\overrightarrow{\mathrm{i}}$ & ה & $\begin{array}{l}0 \\
\infty \\
\infty\end{array}$ & $\wedge$ & $\begin{array}{l}\stackrel{0}{2} \\
\text { in }\end{array}$ & î & $\underset{\sim}{\stackrel{0}{\sim}}$ & & $\stackrel{\text { L }}{\varrho}$ & 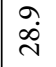 & 2 & $\stackrel{\curvearrowright}{\stackrel{\sim}{\sim}}$ & in & $\stackrel{m}{\sim}$ & 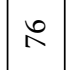 & $\begin{array}{l}0 \\
\stackrel{\sim}{\sim} \\
\end{array}$ & $\tilde{m}$ & ֶి \\
\hline & 8ụuлош & & $\overrightarrow{6}$ & $\stackrel{\ddot{N}}{\ddot{\sim}}$ & 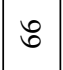 & $\stackrel{0}{\stackrel{i}{i}}$ & $\wedge$ & 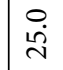 & 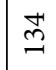 & $\underset{\sim}{\stackrel{\sim}{*}}$ & & 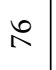 & ڤे & $\stackrel{\infty}{\wedge}$ & $\vec{i}$ & กิ & 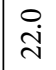 & $\stackrel{\infty}{+}$ & $\stackrel{n}{\stackrel{2}{2}}$ & $\stackrel{t}{n}$ & $\overrightarrow{\mathrm{i}}$ \\
\hline & Kepuns & & $\stackrel{\infty}{-}$ & ̧ે & 2 & $\stackrel{n}{1}$ & in & $\stackrel{9}{\triangleq}$ & F & $\stackrel{0}{n}$ & & 구 & $\stackrel{\circ}{=}$ & $\tilde{m}$ & $\stackrel{\infty}{\infty}$ & $\stackrel{\sim}{\sim}$ & $\begin{array}{l}0 \\
0 \\
0\end{array}$ & in & $\hat{\mathrm{I}}$ & $\stackrel{\vec{n}}{2}$ & $\begin{array}{l}0 \\
\stackrel{0}{0}\end{array}$ \\
\hline & KерхпцеS & & $\stackrel{9}{+}$ & $\begin{array}{l}n \\
0 \\
0\end{array}$ & in & 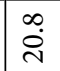 & $\neg$ & $\stackrel{\bullet}{\dot{r}}$ & 2 & $\stackrel{9}{\stackrel{1}{2}}$ & & ले & $\hat{0}$ & $\hat{m}$ & $\stackrel{n}{a}$ & $\stackrel{\infty}{m}$ & $\overrightarrow{6}$ & 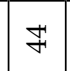 & $\stackrel{\circ}{\stackrel{0}{0}}$ & $\stackrel{\infty}{n}$ & 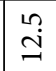 \\
\hline & Кер!. & & ले & $\stackrel{\vartheta}{ \pm}$ & กิ & $\stackrel{2}{2}$ & m & $\hat{\varrho}$ & J & $\stackrel{0}{2}$ & & के & nְ. & 6 & $\stackrel{?}{=}$ & $\stackrel{n}{m}$ & $\stackrel{\infty}{\underset{+}{+}}$ & $\tilde{m}$ & $\begin{array}{l}0 \\
\exists\end{array}$ & $\stackrel{\Omega}{\Omega}$ & $\stackrel{?}{\stackrel{n}{n}}$ \\
\hline $\overrightarrow{\widehat{\sigma}}$ & Керs.nчL & & ஓे & $\stackrel{n}{=}$ & $\vec{m}$ & $\stackrel{\varrho}{\Xi}$ & $m$ & $\hat{\varrho}$ & t & : & & $\infty$ & $\stackrel{1}{\infty}$ & $R$ & $\stackrel{\infty}{\sim}$ & $m$ & $\stackrel{\circ}{\stackrel{\circ}{+}}$ & F & $\stackrel{m}{n}$ & $\stackrel{m}{\sim}$ & $\stackrel{\sigma}{\circ}$ \\
\hline & Керsәирәм & & $\mathscr{F}$ & $\stackrel{\vartheta}{\grave{b}}$ & $\stackrel{n}{m}$ & $\stackrel{m}{n}$ & $\wedge$ & 芦 & 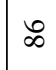 & 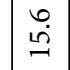 & & 8 & $\stackrel{\Perp}{\stackrel{2}{\Delta}}$ & $\bullet$ & $\stackrel{\circ}{\stackrel{1}{~}}$ & $\hat{m}$ & 窇 & f & $\vec{I}$ & $\stackrel{m}{\sim}$ & $\hat{\sigma}$ \\
\hline & KepsənL & & $\stackrel{\infty}{+}$ & 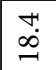 & $\ddot{m}$ & 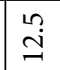 & 6 & $\stackrel{+}{\vec{\lambda}}$ & $\infty$ & $\begin{array}{l}\hat{n} \\
\text { in }\end{array}$ & & $\stackrel{\infty}{+}$ & $\stackrel{\sim}{n}$ & हे & ஸุ & $\hat{n}$ & ف & 7 & $\underline{n}$ & $\stackrel{\infty}{\infty}$ & $\stackrel{\overbrace{}}{ \pm}$ \\
\hline & Кериом & & ले & $\stackrel{\vartheta}{\unlhd}$ & $\dot{m}$ & $\begin{array}{l}\infty \\
\pm \\
\end{array}$ & m & $\hat{\circ}$ & $\bar{\infty}$ & $\begin{array}{l}\sigma \\
\pm \\
\pm\end{array}$ & & $\mathbb{F}$ & $\vec{i}$ & in & $\stackrel{\curvearrowright}{\unlhd}$ & $\vec{n}$ & $\vec{m}$ & $m$ & $\stackrel{o}{i}$ & $\stackrel{0}{0}$ & $\vec{m}$ \\
\hline & त्ञँ & & $\vec{i}$ & 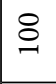 & 芯 & \& & $\stackrel{\infty}{\sim}$ & 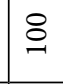 & 䓟 & 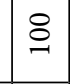 & & $\hat{ర}$ & 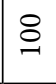 & $\begin{array}{l}\infty \\
\infty \\
\infty\end{array}$ & 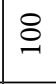 & $\stackrel{\sim}{\sim}$ & 8 & $\stackrel{\stackrel{2}{N}}{\widehat{N}}$ & 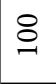 & 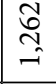 & 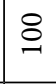 \\
\hline & & & $\stackrel{\circ}{z}$ & $a^{\circ}$ & $\stackrel{\circ}{z}$ & $\partial^{\circ}$ & z & $a^{\circ}$ & $\stackrel{\circ}{z}$ & $a^{\circ}$ & & $\stackrel{2}{z}$ & $0^{\circ}$ & $\stackrel{2}{z}$ & $0^{\circ}$ & $\stackrel{0}{z}$ & $0^{\circ}$ & $\ddot{z}$ & $a^{\circ}$ & $\stackrel{0}{z}$ & $\therefore$ \\
\hline & & & & $\overline{8}$ & & 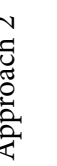 & & 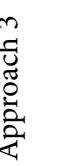 & & $\ominus$ & & $\begin{array}{l} \\
\\
\\
0 \\
0\end{array}$ & & & & 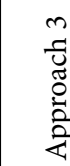 & 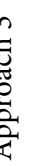 & 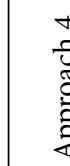 & & & \\
\hline
\end{tabular}


Table 2. Descriptive for day per week

\begin{tabular}{|c|c|c|c|c|c|c|c|c|}
\hline & \multirow{2}{*}{$N$} & \multirow{2}{*}{ Mean } & \multirow{2}{*}{ Std. deviation } & \multirow{2}{*}{ Std. error } & \multicolumn{2}{|c|}{ 95\% confidence interval for mean } & \multirow{2}{*}{ Minimum } & \multirow{2}{*}{ Maximum } \\
\hline & & & & & Lower bound & Upper bound & & \\
\hline \multicolumn{9}{|c|}{ 3-leg intersection } \\
\hline Approach 1 & 7 & 37.2857 & 10.19337 & 3.85273 & 27.8584 & 46.7130 & 18.00 & 48.00 \\
\hline Approach 2 & 7 & 37.7143 & 12.44607 & 4.70417 & 26.2036 & 49.2250 & 19.00 & 55.00 \\
\hline Approach 3 & 7 & 4.0000 & 2.08167 & 0.78680 & 2.0748 & 5.9252 & 1.00 & 7.00 \\
\hline Total & 21 & 26.3333 & 18.46167 & 4.02867 & 17.9297 & 34.7370 & 1.00 & 55.00 \\
\hline \multicolumn{9}{|c|}{ 4-leg intersection } \\
\hline Approach 1 & 7 & 51.8571 & 11.36410 & 4.29523 & 41.3471 & 62.3672 & 39.00 & 68.00 \\
\hline Approach 2 & 7 & 55.4286 & 15.06494 & 5.69401 & 41.4958 & 69.3613 & 32.00 & 70.00 \\
\hline Approach 3 & 7 & 33.7143 & 4.57217 & 1.72812 & 29.4857 & 37.9428 & 25.00 & 38.00 \\
\hline Approach 4 & 7 & 39.2857 & 5.87975 & 2.22234 & 33.8479 & 44.7236 & 32.00 & 47.00 \\
\hline Total & 28 & 45.0714 & 13.16541 & 2.48809 & 39.9664 & 50.1764 & 25.00 & 70.00 \\
\hline
\end{tabular}

Table 3. ANOVA for day per week per approach

\begin{tabular}{|c|c|c|c|c|c|}
\hline & Sum of squares & $d f$ & Mean square & $F$ & Sig. \\
\hline \multicolumn{6}{|c|}{ 3-leg intersection } \\
\hline Between groups & 5237.810 & 2 & 2618.905 & 29.857 & 0.000 \\
\hline Within groups & 1578.857 & 18 & 87.714 & & \\
\hline Total & 6816.667 & 20 & & & \\
\hline \multicolumn{6}{|c|}{ 4-leg intersection } \\
\hline Between groups & 2210.429 & 3 & 736.810 & 7.161 & 0.001 \\
\hline Within groups & 2469.429 & 24 & 102.893 & & \\
\hline Total & 4679.857 & 27 & & & \\
\hline
\end{tabular}

Table 4. PostHoc Tukey test for different approaches per days

\begin{tabular}{|c|c|c|c|c|c|c|}
\hline \multirow{2}{*}{ Approach $(I)$} & \multirow{2}{*}{ Approach $(J)$} & \multirow{2}{*}{ Mean difference $(I-J)$} & \multirow{2}{*}{ Std. Error } & \multirow{2}{*}{ Sig. } & \multicolumn{2}{|c|}{ 95\% confidence interval } \\
\hline & & & & & Lower bound & Upper bound \\
\hline \multicolumn{7}{|c|}{ 3-leg intersection } \\
\hline \multirow{2}{*}{1} & 2 & -0.42857 & 5.00612 & 0.996 & -13.2050 & 12.3479 \\
\hline & 3 & $33.28571^{*}$ & 5.00612 & 0.000 & 20.5093 & 46.0621 \\
\hline \multirow{2}{*}{2} & 1 & 0.42857 & 5.00612 & 0.996 & -12.3479 & 13.2050 \\
\hline & 3 & $33.71429^{*}$ & 5.00612 & 0.000 & 20.9379 & 46.4907 \\
\hline \multirow{2}{*}{3} & 1 & $-33.28571^{*}$ & 5.00612 & 0.000 & -46.0621 & -20.5093 \\
\hline & 2 & $-33.71429^{*}$ & 5.00612 & 0.000 & -46.4907 & -20.9379 \\
\hline \multicolumn{7}{|c|}{ 4-leg intersection } \\
\hline \multirow{3}{*}{1} & 2 & -3.57143 & 5.42199 & 0.911 & -18.5286 & 11.3857 \\
\hline & 3 & $18.14286^{*}$ & 5.42199 & 0.013 & 3.1857 & 33.1000 \\
\hline & 4 & 12.57143 & 5.42199 & 0.122 & -2.3857 & 27.5286 \\
\hline \multirow{3}{*}{2} & 1 & 3.57143 & 5.42199 & 0.911 & -11.3857 & 18.5286 \\
\hline & 3 & $21.71429^{*}$ & 5.42199 & 0.003 & 6.7571 & 36.6714 \\
\hline & 4 & $16.14286^{\star}$ & 5.42199 & 0.031 & 1.1857 & 31.1000 \\
\hline \multirow{3}{*}{3} & 1 & $-18.14286^{*}$ & 5.42199 & 0.013 & -33.1000 & -3.1857 \\
\hline & 2 & $-21.71429^{*}$ & 5.42199 & 0.003 & -36.6714 & -6.7571 \\
\hline & 4 & -5.57143 & 5.42199 & 0.735 & -20.5286 & 9.3857 \\
\hline \multirow{3}{*}{4} & 1 & -12.57143 & 5.42199 & 0.122 & -27.5286 & 2.3857 \\
\hline & 2 & $-16.14286^{*}$ & 5.42199 & 0.031 & -31.1000 & -1.1857 \\
\hline & 3 & 5.57143 & 5.42199 & 0.735 & -9.3857 & 20.5286 \\
\hline
\end{tabular}

Note: ${ }^{*}$ - the mean difference is significant at the 0.05 level. 
Table 5. ANOVA per days per week

\begin{tabular}{|l|c|c|c|c|c|}
\cline { 2 - 6 } \multicolumn{7}{c|}{} & $\begin{array}{c}\text { Sum of } \\
\text { squares }\end{array}$ & $d f$ & $\begin{array}{c}\text { Mean } \\
\text { square }\end{array}$ & $F$ & Sig. \\
\hline 3-leg intersection \\
\hline Between groups & 151.819 & 6 & 25.303 & 0.876 & 0.536 \\
\hline Within groups & 404.207 & 14 & 28.872 & & \\
\hline Total & 556.026 & 20 & & & \\
\hline \multicolumn{7}{|c|}{ 4-leg intersection } \\
\hline Between groups & 109.397 & 6 & 18.233 & 4.266 & 0.006 \\
\hline Within groups & 89.755 & 21 & 4.274 & & \\
\hline Total & 199.152 & 27 & & & \\
\hline
\end{tabular}

Table 6. ANOVA per part of the day

\begin{tabular}{|c|c|c|c|c|c|}
\hline & $\begin{array}{l}\text { Sum of } \\
\text { squares }\end{array}$ & $d f$ & $\begin{array}{l}\text { Mean } \\
\text { square }\end{array}$ & $F$ & Sig. \\
\hline \multicolumn{6}{|c|}{ 3-leg intersection } \\
\hline Between groups & 332.300 & 3 & 110.767 & 2.447 & 0.139 \\
\hline Within groups & 362.160 & 8 & 45.270 & & \\
\hline Total & 694.460 & 11 & & & \\
\hline \multicolumn{6}{|c|}{ 4-leg intersection } \\
\hline Between groups & 647.713 & 3 & 215.904 & 11.665 & 0.001 \\
\hline Within groups & 222.107 & 12 & 18.509 & & \\
\hline Total & 869.820 & 15 & & & \\
\hline
\end{tabular}

Table 7. ANOVA per second of RLR after red-light onset

\begin{tabular}{|l|c|c|c|c|c|}
\cline { 2 - 6 } \multicolumn{7}{c|}{} & $\begin{array}{c}\text { Sum of } \\
\text { squares }\end{array}$ & $d f$ & $\begin{array}{c}\text { Mean } \\
\text { square }\end{array}$ & $F$ & Sig. \\
\hline 3-leg intersection \\
\hline Between groups & 6514.503 & 7 & 930.643 & 85.741 & 0.000 \\
\hline Within groups & 173.667 & 16 & 10.854 & & \\
\hline Total & 6688.170 & 23 & & & \\
\hline \multicolumn{7}{|c|}{ 4-leg intersection } \\
\hline Between groups & 6340.690 & 7 & 905.813 & 51.068 & 0.000 \\
\hline Within groups & 425.698 & 24 & 17.737 & & \\
\hline Total & 6766.388 & 31 & & & \\
\hline
\end{tabular}

Table 8. ANOVA per vehicle type

\begin{tabular}{|l|c|c|c|c|c|}
\cline { 2 - 6 } \multicolumn{7}{c|}{} & $\begin{array}{c}\text { Sum of } \\
\text { squares }\end{array}$ & $d f$ & $\begin{array}{c}\text { Mean } \\
\text { square }\end{array}$ & $F$ & Sig. \\
\hline \multicolumn{7}{|c|}{ 3-leg intersection } \\
\hline Between groups & 12321.663 & 4 & 3080.416 & 215.736 & 0.000 \\
\hline Within groups & 142.787 & 10 & 14.279 & & \\
\hline Total & 12464.449 & 14 & & & \\
\hline \multicolumn{7}{|c|}{ 4-leg intersection } \\
\hline Between groups & 8091.047 & 4 & 2022.762 & 220.701 & 0.000 \\
\hline Within groups & 137.478 & 15 & 9.165 & & \\
\hline Total & 8228.525 & 19 & & & \\
\hline
\end{tabular}

Applying ANOVA was determined that on 4-leg intersection is a different driver behavior related to RLR during the days of the week as well as the period during the day, which is not characteristic for the 3-leg intersection. So the 3-leg intersection users make RLR unrelated mentioned features, which means that the same measures can be implemented permanently (during the week, days, etc.), whereas this is not the case with the 4-leg intersection.

In order to forecast in which second after the redlight onset RLR will occur, a corresponding test was done matching the number of RLR with the appropriate distributions. The test was done for every approach separately and for whole intersection as well. For the 3-leg intersection overall, it was shown that Mean for second of RLR after red-light onset was 2.67, Std. Deviation was 2.51 , Variance was 6.29 , while 75 th percentile counts 3, and for 4-leg intersection overall, it was shown that Mean for second of RLR after red-light onset was 2.68 , Std. Deviation was 2.4 , Variance was 5.75 , while 75th percentile counts 3 (Table 9).

When test-matching data of RLR with the appropriate statistical distributions was conducted, RLR from 8th second have not been taken into account in order to avoid distortion of distribution and false number. Data matching of RLR number and the possibility of forecasting defined based on the first seven seconds for the approaches and overall was conducted by using RLR frequencies of each second after red-light onset.

Table 9. Descriptive and 75th percentile of RLR second after red-light onset

\begin{tabular}{|l|c|c|c|c|c|c|}
\cline { 2 - 7 } \multicolumn{1}{c|}{} & Nvalid & Missing & Mean & Std. deviation & Variance & Percentiles 75 \\
\hline \multicolumn{7}{|c|}{ 3-leg intersection } \\
\hline Approach 1 & 261 & 292 & 2.4674 & 2.39789 & 5.750 & 2.0000 \\
\hline Approach 2 & 264 & 289 & 2.8598 & 2.58382 & 6.676 & 4.0000 \\
\hline Approach 3 & 28 & 525 & 2.8214 & 2.72238 & 7.411 & 4.7500 \\
\hline Total & 553 & 0 & 2.6727 & 2.50787 & 6.289 & 3.0000 \\
\hline \multicolumn{7}{|c|}{ 4-leg intersection } \\
\hline Approach 1 & 363 & 899 & 2.35 & 2.228 & \multicolumn{4}{|c|}{4.962} & 2.0000 \\
\hline Approach 2 & 388 & 874 & 2.53 & 2.389 & 5.707 & 2.0000 \\
\hline Approach 3 & 236 & 1026 & 3.28 & 2.719 & 7.392 & 4.0000 \\
\hline Approach 4 & 275 & 987 & 2.83 & 2.241 & 5.021 & 3.0000 \\
\hline Total & 1262 & 0 & 2.68 & 2.399 & 5.754 & 3.0000 \\
\hline
\end{tabular}


It was shown that RLR per second after red-light onset has the best match with Cubic distribution, for both intersections. Actually Cubic distribution could forecast the second of RLR after red-light onset with very high probability. For the 3-leg intersection $R$ square for Cubic, distribution for approaches 1 and 2, and for the intersection overall was 0.99 , while for the approach 3 it was 0.95, and for 4-leg intersection distribution for approaches 3 and 4 , and for the intersection overall was 0.99 , and for approach 1 was 0.98 , and for approach 2 was 0.97 (Table 10). The analytical formulation of the cubic distribution for 3-leg intersection in overall is:

$$
Y=-0.767 \cdot X^{3}+11.869 \cdot X^{2}-59.679 \cdot X+99.329
$$

and for 4-leg intersection in overall is:

$$
Y=-0.339 \cdot X^{3}+6.548 \cdot X^{2}-41.587 \cdot X+87.597 .
$$

Furthermore, in term of RLR issue it is especially important to define some kind of risk indicator that could evaluate RLR accident risk. Risk indicator called DD takes into consideration the total number of RLR and the number of dangerous situations resulting from RLR. At the time of this research at the 3-leg intersection from 553 RLR 18 dangerous situations occurred and at the 4-leg intersection from 1262 RLR 39 dangerous situations (extremely fast reaction is required for accident avoidance) occurred, such as endangering pedestrians at crossings, forced braking to avoid rear-end collisions and turning and braking in order to avoid collision with those who turn left. Dangerous situations were identified by the so-called scientific observation, similarly to traditional traffic conflict technique, but not the same. For example, observer has to decide and register if some observed situation is dangerous or not, having in mind required road user reaction due to accident avoidance. DD indicates the risk of turning RLR into an accident, and the greater DD means greater possibility of accidents occurring. DD could be used also after application of appropriate countermeasures. In case that DD value is lower after applying of countermeasures, it leads to conclusion that the countermeasures were effective. In opposite case, if after the applications of countermeasures DD value is equal or higher than before it could be concluded that countermeasures were not effective.

Therefore, DD for the whole survey 3-leg intersection is:

$$
D D=\frac{N o D S}{N o R L R} \cdot 100=\frac{18}{553} \cdot 100=3.3
$$

and for 4-leg intersection is:

$$
D D=\frac{N o D S}{N o R L R} \cdot 100=\frac{39}{1262} \cdot 100=3.1,
$$

where: $D D$ - danger degree; NoDS - number of dangerous situations caused by RLR; NoRLR - number of RLR.

Results of DD calculation for the 3-leg intersection shows that approach 3 has the highest risk, despite smallest NoDS. Results of DD calculation for the 4-leg intersection shows that approach 2 has the highest risk (Table 11). Comparing 3-leg and 4-leg intersections, 3-leg intersection has higher probability of accident oc-

\begin{tabular}{|c|c|c|c|}
\hline & NoDS & NoRLR & DD \\
\hline \multicolumn{4}{|c|}{ 3-leg intersection } \\
\hline Approach 1 & 8 & 261 & 3.1 \\
\hline Approach 2 & 9 & 264 & 3.4 \\
\hline Approach 3 & 1 & 28 & 3.6 \\
\hline Total & 18 & 553 & 3.3 \\
\hline \multicolumn{4}{|c|}{ 4-leg intersection } \\
\hline Approach 1 & 12 & 363 & 3.3 \\
\hline Approach 2 & 15 & 388 & 3.9 \\
\hline Approach 3 & 7 & 236 & 3.0 \\
\hline Approach 4 & 5 & 275 & 1.8 \\
\hline Total & 39 & 1262 & 3.1 \\
\hline
\end{tabular}
curance.

Table 11. DD for the intersection overall and for the approaches

Table 10. Matching of RLR second after red-light onset with Cubic distribution for the approaches and for the intersection overall

\begin{tabular}{|l|c|c|c|c|c|c|c|c|c|c|}
\cline { 2 - 11 } \multicolumn{1}{c|}{} & \multicolumn{9}{c|}{ Model summary } & \multicolumn{4}{c|}{ Parameter estimates } \\
\cline { 2 - 12 } \multicolumn{1}{c|}{} & $R$ square & $F$ & $d f 1$ & $d f 2$ & Sig. & Constant & $b 1$ & $b 2$ & $b 3$ \\
\hline \multicolumn{9}{|c|}{ 3-leg intersection } \\
\hline Approach 1 & 0.994 & 169.119 & 3 & 3 & 0.001 & 106.714 & -64.507 & 12.774 & -0.819 \\
\hline Approach 2 & 0.988 & 83.748 & 3 & 3 & 0.002 & 89.700 & -52.300 & 10.244 & -0.656 \\
\hline Approach 3 & 0.954 & 20.666 & 3 & 3 & 0.017 & 122.800 & -86.350 & 19.479 & -1.386 \\
\hline Total & 0.992 & 130.500 & 3 & 3 & 0.001 & 99.329 & -59.679 & 11.869 & -0.767 \\
\hline \multicolumn{8}{|c|}{ 4-leg intersection } \\
\hline Approach 1 & 0.983 & 58.372 & 3 & 3 & 0.004 & 108.280 & -59.240 & 10.673 & -0.629 \\
\hline Approach 2 & 0.968 & 30.115 & 3 & 3 & 0.010 & 100.166 & -50.989 & 8.411 & -0.448 \\
\hline Approach 3 & 0.999 & 1073.837 & 3 & 3 & 0.000 & 73.207 & -30.171 & 4.191 & -0.197 \\
\hline Approach 4 & 0.996 & 281.957 & 3 & 3 & 0.000 & 53.740 & -13.850 & 0.287 & -0.091 \\
\hline Total & 0.987 & 77.658 & 3 & 3 & 0.002 & 87.597 & -41.587 & 6.548 & -0.339 \\
\hline
\end{tabular}




\section{Discussion and Conclusions}

Because of the dangerous situations caused by RLR, and particularly because of the accidents occurring possibility with more severe consequences, it is necessary to collect certain number and kind of data at signalized intersections and carry out certain analysis to determine whether those data may indicate the potential countermeasures to reduce and to prevent RLR.

Although there is already a well-defined protocol to define and identify the 'dangerous situations' by using traditional conflict technique, we used subjective approach when assessing dangerous situations, because basic identifying of the dangerous situation by using traditional conflict technique takes only time to collision. In our opinion besides time to collision, it has to be used space to collision and road users' speed.

It was necessary to analyse whether the approaches differ in the number of RLR. Traffic volume at the main direction was greater than traffic volume at side approach, and the number of RLR at main direction was also greater than number of RLR on a side approach. That indicates that drivers often made RLR at the main direction. Statistically significant differences between the approaches were confirmed using ANOVA analysis and PostHoc Tukey test.

ANOVA analysis on the number of RLR per days of the week and per parts of the day have showed that there were no statistically significant differences for 3-leg, but for 4-leg there were. Total number of RLR at the intersection on Sundays was about two times lower compared to other days of the week, while other days had a similar number of RLR. RLR enforcement from Monday until Saturday would eventually reduce the number of RLR.

According to the ANOVA there are also no significant statistical dependence in the number of RLR per the part of the day for 3-leg and 4-leg there more. Descriptive statistics have showed that most RLR occur in the afternoon (over a third of all RLR), while least RLR occurred in the evening or at night hours (about one third compared to afternoon hours). This conclusion could significantly contribute to defining, planning and implementation of RLR enforcement in certain periods during the day. The number of RLR by the approaches and overall, has showed that side approach (approaches 3 and 4) per part of the day differs from the main direction because the majority of RLR occurred during the afternoon at the main directions (approaches 1 and 2). In the same part of the day the minimal number of RLR on side approach occured. On the other hand, at the approach 3, most of RLR occurred during evening or night period, when at the main direction was a fewer number of RLR.

For a more detailed explanation of drivers' behavior, some additional research such as questionnaire, etc, has to be done. However, according to available data it could be concluded that the reasons for a higher number of RLR occurring during the afternoon period on the main approaches, and during the evening period on the secondary approach are: traffic volume and perceived risk of RLR enforcement. Traffic volume on the main direction in the afternoon period has the highest volume compared to other periods. Additionally, drivers, having in mind lack of enforcement, easily decide to make RLR violation. On the other hand, in the evening period, because of the very low traffic volume, drivers often decide not to wait for the green-light, and to make RLR violation. This is particularly expressed when there are no vehicles at the main direction.

It was particularly interesting to determine whether certain categories of vehicles often make RLR violations and it was shown that there were significant differences. Almost $80 \%$ for 3 -leg and over $60 \%$ for 4 -leg, of all RLR were done by passenger cars, which approximately corresponds the share of passenger cars in the traffic flow. ANOVA analysis showed statistically significant difference when considering category of vehicle that did RLR. That means that there were a different number of RLR violations due to different vehicle categories, similar found by Huang and Chin (2009). Considering the total number of vehicles in traffic flow and number of RLR violation in each particular vehicle category, it could be concluded that the most dangerous vehicle category is passenger cars, comparing to Yan et al. (2005) where truck drivers have higher red-light violation rate. One of the most important goals for decision-makers due to RLR is to reduce the total number of RLR, maybe the second or the third goal is to reduce RLR rates. Although most of all RLR were done by passenger cars, which approximately corresponds the share of passenger cars in the traffic flow it could not be concluded that passenger car drivers were no more dangerous that other drivers. On the contrary, it could be concluded that passenger car drivers were more dangerous, because, in our opinion, RLR analysis in absolute number is more important, compared to RLR rates analysis (relative numbers). For example, it is better to save 10 lives at the intersection with 100 RLR, than 5 lives at the intersection with 10 RLR, although rates are telling a different story. In most cases passenger car drivers are not professional drivers, so the best effect on those drivers should be sought through the mechanisms that can reach the general public such as campaigns, information etc.

Observing Mean and Std. Deviation for the seconds of RLR after red-light onset as well as taking 75th percentile it could be concluded that most of RLR occur in the first 3 seconds after red-light onset, compared to Limanond et al. (2010) who showed the mean time of RLR was 4.13 seconds after onset of red phase. Countermeasures that could affect on the reduction of this problem are introduction of counters, extension of the protective time between red-light phases for opposite direction (for about 3 seconds), introduction of RLC etc. Protective time is a part of the cycle that ensures that vehicleentering intersection in the last second of green-light phase will pass intersection safe, regard vehicle-entering intersection in the first second of green-light phase at opposite direction. Bearing in mind that some drivers when moving through the intersection at the end of the green phase speed up to cross the intersection, but also 
that the 75th percentile of RLR second after RL onset is $3^{\text {rd }}$ second, this period is extremely critical for the occurrence of dangerous situations and accidents. Therefore, the extension of the protective time could decrease the risks due to RLR.

Danger Degree (DD) was proposed as a rate between the number of dangerous situations and the number of RLR, which could be implemented by using the 'before-after' concept. Simply by comparing $D D_{\text {before }}$ and $D D_{\text {after }}$, the efficiency of the implemented measures could be determined. In further researches after the implementation of the proposed countermeasures (extension of protective time, counters, RLC, etc) it will be necessary to collect data proposed in this paper and to define efficiency. Each of the applied countermeasures would be analysed separately without mutual influence. In future publications DD should be thoroughly analysed, by including calculation of the more or less danger situation, similarly to the traditional method of the traffic conflict technique.

\section{Acknowledgements}

This paper is based on the project TR36027 'Software Development and National Database for Strategic Management and Development of Transportation Means and Infrastructure in Road, Rail, Air and Inland Waterways Transport using the European Transport Network Models', which is supported by the Ministry of Science and Technological Development of Republic of Serbia (2011-2014).

\section{References}

Abdel-Aty, M.; Keller, J.; Brady, P. A. 2005. Analysis of types of crashes at signalized intersections by using complete crash data and tree-based regression, Transportation Research Record: Journal of the Transportation Research Board 1908: 37-45. http://doi.org/10.3141/1908-05

Adams, J. S.; VanDrasek, B. J. 2009. Automated Enforcement of Red-Light Running \& Speeding Laws in Minnesota: Bridging Technology and Public Policy. Research Report CTS 09-26. Center for Transportation Studies, University of Minnesota. 101 p. Available from Internet: https://conservancy. umn.edu/handle/11299/97666

Awadallah, F. 2013. Yellow and all-red intervals: how to improve safety and reduce delay?, International Journal for Traffic and Transport Engineering 3(2): 159-172. http://doi.org/10.7708/ijtte.2013.3(2).05

Awadallah, F. 2009. A legal approach to reduce red light running crashes, Transportation Research Record: Journal of the Transportation Research Board 2096: 102-107. http://doi.org/10.3141/2096-14

Çelik, A. K.; Senger, Ö. 2014. Risk factors affecting fatal versus non-fatal road traffic accidents: the case of Kars province, Turkey, International Journal for Traffic and Transport Engineering 4(3): 339-351. http://doi.org/10.7708/ijtte.2014.4(3).07

De Luca, M. 2015. A comparison between prediction power of artificial neural networks and multivariate analysis in road safety management, Transport.

http://doi.org/10.3846/16484142.2014.995702
De Luca, M.; Mauro, R.; Russo, F.; Dell'Acqua, G. 2011. Beforeafter freeway accident analysis using cluster algorithms, Procedia - Social and Behavioral Sciences 20: 723-731. http://doi.org/10.1016/j.sbspro.2011.08.080

EC. 2008. Proposal for a Directive of the European Parliament and of the Council Facilitating Cross-Border enforcement in the Field of Road Safety (Presented by the Commission of the European Communities). COM(2008) 151 final. 35 p. Available from Internet: http://eur-lex.europa.eu/legal-content/ EN/TXT/PDF/?uri = CELEX:52008PC0151\&from = EN

Elmitiny, N.; Yan, X.; Radwan, E.; Russo, C.; Nashar, D. 2010. Classification analysis of driver's stop/go decision and redlight running violation, Accident Analysis \& Prevention 42(1): 101-111. http://doi.org/10.1016/j.aap.2009.07.007

Fitzsimmons, E. J.; Hallmark, S.; McDonald, T.; Orellana, M.; Matulac, D. 2007. The Effectiveness of Iowa's Automated Red Light Running Enforcement Programs. Final Report. Iowa Department of Transportation. 139 p. Available from Internet: http://www.intrans.iastate.edu/reports/rlr-phase2.pdf

Fitzsimmons, E. J.; Hallmark, S. L.; Orellana, M.; McDonald, T.; Matulac, D. 2009. Investigation of Violation Reduction at intersection approaches with automated red light running enforcement cameras in Clive, Iowa, using a crosssectional analysis, Journal of Transportation Engineering 135(12): 984-989.

http://doi.org/10.1061/(ASCE)TE.1943-5436.0000079

Hallmark, S.; Oneyear, N.; McDonald, T. 2012. Toolbox of Countermeasures to Reduce Red Light Running. Final Report. Midwest Transportation Consortium. 46 p. Available from Internet: http://www.intrans.iastate.edu/research/ documents/research-reports/RLR_toolbox_w_cvr.pdf

Hallmark, S.; Oneyear, N.; McDonald, T. 2011. Evaluating the Effectiveness of Red Light Running Camera Enforcement in Cedar Rapids and Developing Guidelines for Selection and Use of Red Light Running Countermeasures. Final Report. Midwest Transportation Consortium. 68 p. Available from Internet: http://www.ctre.iastate.edu/research/detail. cfm?projectID = 1284663747

Huang, H.; Chin, H. C. 2009. Disaggregate propensity study on red light running crashes using quasi-induced exposure method, Journal of Transportation Engineering 135(3): 104-111.

http://doi.org/10.1061/(ASCE)0733-947X(2009)135:3(104)

Ismail, K.; Sayed, T.; Saunier, N.; Lim, C. 2009. Automated analysis of pedestrian-vehicle conflicts using video data, Transportation Research Record: Journal of the Transportation Research Board 2140: 44-54. http://doi.org/10.3141/2140-05

Johnson, M.; Newstead, S.; Charlton, J.; Oxley, J. 2011. Riding through red lights: The rate, characteristics and risk factors of non-compliant urban commuter cyclists, Accident Analysis \& Prevention 43(1): 323-328.

http://doi.org/10.1016/j.aap.2010.08.030

Limanond, T.; Prabjabok, P.; Tippayawong, K. 2010. Exploring impacts of countdown timers on traffic operations and driver behavior at a signalized intersection in Bangkok, Transport Policy 17(6): 420-427. http://doi.org/10.1016/j.tranpol.2010.04.009

Liu, Y.; Chang, G.-L.; Yu, J. 2012. Empirical study of driver responses during the yellow signal phase at six Maryland intersections, Journal of Transportation Engineering 138(1): 31-42.

http://doi.org/10.1061/(ASCE)TE.1943-5436.0000278 
Long, K.; Han, L. D.; Yang, Q. 2011. Effects of countdown timers on driver behavior after the yellow onset at Chinese intersections, Traffic Injury Prevention 12(5): 538-544. http://doi.org/10.1080/15389588.2011.593010

Ma, W.; Liu, Y.; Yang, X. 2010. Investigating the impacts of green signal countdown devices: empirical approach and case study in China, Journal of Transportation Engineering 136(11): 1049-1055. http://doi.org/10.1061/(ASCE)TE.1943-5436.0000181

Palat, B.; Delhomme, P. 2012. What factors can predict why drivers go through yellow traffic lights? An approach based on an extended theory of planned behavior, Safety Science 50(3): 408-417. http://doi.org/10.1016/j.ssci.2011.09.020

Pesic, D.; Vujanic, M.; Lipovac, K.; Antic, B. 2011. Analysis of possibility for traffic safety improvement based on Serbian traffic violation database analysis, Scientific Research and Essays 6(29): 6140-6151. http://doi.org/10.5897/SRE11.1272

Phillips, R. O.; Bjørnskau, T.; Hagman, R.; Sagberg, F. 2011. Reduction in car-bicycle conflict at a road-cycle path intersection: evidence of road user adaptation?, Transportation Research Part F: Traffic Psychology and Behaviour 14(2): 87-95. http://doi.org/10.1016/j.trf.2010.11.003

Porter, B. E.; England, K. J. 2000. Predicting red-light running behavior: a traffic safety study in three urban settings, Journal of Safety Research 31(1): 1-8.

http://doi.org/10.1016/S0022-4375(99)00024-9

Retting, R. A.; Chapline, J. F; Williams, A. F. 2002. Changes in crash risk following re-timing of traffic signal change intervals, Accident Analysis \& Prevention 34(2): 215-220. http://doi.org/10.1016/S0001-4575(01)00016-1

Retting, R. A.; Williams, A. F.; Farmer, C. M.; Feldman, A. F. 1999a. Evaluation of red light camera enforcement in Oxnard, California, Accident Analysis \& Prevention 31(3): 169-174. http://doi.org/10.1016/S0001-4575(98)00059-1

Retting, R. A.; Williams, A. F.; Farmer, C. M.; Feldman, A. F. 1999b. Evaluation of red light camera enforcement in Fairfax, VA., USA, ITE Journal 69(8): 30-34.

Retting, R.; Williams, A.; Greene, M. 1998. Red-light running and sensible countermeasures: summary of research findings, Transportation Research Record: Journal of the Transportation Research Board 1640: 23-26. http://doi.org/10.3141/1640-04

Saunier, N.; Sayed, T. 2007. Automated analysis of road safety with video data, Transportation Research Record: Journal of the Transportation Research Board 2019: 57-64. http://doi.org/10.3141/2019-08

Schultz, G. G.; Peterson, R.; Eggett, D. L.; Giles, B. C. 2007. Effectiveness of blank-out overhead dynamic advance warning signals at high-speed signalized intersections, Journal of Transportation Engineering 133(10): 564-571.

http://doi.org/10.1061/(ASCE)0733-947X(2007)133:10(564)

Smith, D.; McFadden, J.; Passetti, K. 2000. Automated enforcement of red light running technology and programs: a review, Transportation Research Record: Journal of the Transportation Research Board 1734: 29-37. http://doi.org/10.3141/1734-05

Tiwari, G.; Bangdiwala, S.; Saraswat, A.; Gaurav, S. 2007. Survival analysis: pedestrian risk exposure at signalized intersections, Transportation Research Part F: Traffic Psychology and Behaviour 10(2): 77-89.

http://doi.org/10.1016/j.trf.2006.06.002
Wu, C.; Yao, L.; Zhang, K. 2012. The red-light running behavior of electric bike riders and cyclists at urban intersections in China: an observational study, Accident Analysis \& Prevention 49: 186-192. http://doi.org/10.1016/j.aap.2011.06.001

Yan, X.; Radwan, E.; Birriel, E. 2005. Analysis of red light running crashes based on quasi-induced exposure and multiple logistic regression method, Transportation Research Record: Journal of the Transportation Research Board 1908: 70-79. http://doi.org/10.3141/1908-09

Yan, X.; Radwan, E.; Guo, D.; Richards, S. 2009. Impact of "signal ahead" pavement marking on driver behavior at signalized intersections, Transportation Research Part F: Traffic Psychology and Behaviour 12(1): 50-67. http://doi.org/10.1016/j.trf.2008.07.002 